\title{
ТВОРЧЕСТВО КАК ИНТЕГРАТИВНЫЙ МЕХАНИЗМ ПСИХИКИ
}

\section{CREATIVITY AS THE INTEGRATION MECHANISM OF PSYCHICS}

I. Shemet

Summary: The article describes the understanding of creativity from the point of view of the author's concept of integration of the psyche. Creativity realizes the basic need for the integration of the psyche and arises on the basis of the development of the emotional sphere. Learning destroys creativity. Creativity characterizes the highest level of integration of the psyche.

Keywords: creativity, integrative mechanisms of the psyche, level of integration of the psyche.

\author{
Шемет Ирина Сергеевна \\ Д.nсх.н., АНО ВПО “Национальный Институт имени \\ Екатерины Великой" г. Москва \\ irashemet@yandex.ru
}

Аннотация: В статье изложено понимание творчества с позиции авторской концепции интеграции психики. Творчество реализует базовую потребность в интеграции психики и возникает на основе развития эмоциональной сферы. Обучение уничтожает творчество. Творчество характеризует высший уровень интеграции психики.

Ключевые слова: творчество, интегративные механизмы психики, уровень интеграции психики.

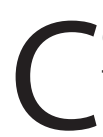
овременные тенденции развития общества востребуют и, одновременно, высвобождают огромное количество человеческих ресурсов - в первую очередь, творческий потенциал отдельного человека. Феномен творчества перешел из границ искусства в повседневную жизнь миллионов людей, в связи с чем, является самостоятельной и одновременно многоплановой темой для изучения, которая представляет интерес не только для психологии, но и для целого ряда наук, таких как философия, социология, медицина, экономика. Из общей структуры этой комплексной проблемы можно выделить некоторые исключительно психологические аспекты. Исследование творчества в качестве интегративного механизма психики является весьма актуальным для современного общества, поскольку дает возможность социально-педагогического ответа на рост психических отклонений у населения, который связан не только с социальными условиями, но и, в первую очередь, с индивидуальными особенностями личности.

Наше понимание творчества основано на авторской концепции интеграции психики. Мы понимаем психику как систему управления жизнью и поведением индивида. Интегративный подход предполагает, что психика является открытой, самоорганизующейся системой, и имеет механизмы поддержания целостности структуры и функции, по аналогии с биологическими механизмами гомеостаза. Мы называем их «интегративные механизмы психики», которые реализуют базовую потребность индивида - самосохранение в процессе развития.

Интегративные механизмы психики не являются отдельными психическими процессами или состояниями, они представляют собой сложные функции, встроен- ные в другие системы управления жизнью, поведением, общением и деятельностью. Можно выделить следующие интегративные механизмы психики: сон (базовый биологический механизм) и сноподобные состояния, связное осознанное дыхание, взаимосвязь с природой, расслабление и спонтанное движение тела, положительные эмоции и эмоциональную память, повторное переживание и осознавание прошлого опыта, мышление, созидательную деятельность и творчество, социальную интеграцию, любовь и духовную интеграцию [14, с. 6].

Исходя из приведенной концепции, творчество это интегративный механизм психики, результатом которого является приведение психики в более интегративное, т. е. целостное состояние. С позиций концепции интеграции психики творчество понимается максимально широко, а именно: как созидательная (конструктивная) активность, в противовес разрушительной (деструктивной) активности. Необходимым аспектом творчества является самодетерминация. Таким образом, творчество как интегративный механизм психики - это самодетерминированная созидательная активность. Она может быть направлена на самого себя, а также на физическое и социальное окружение. Если ребенок сам разложил по полкам свои игрушки, посадил цветы в палисаднике, помог младшей сестренке одеться - это будет творчество в широком смысле этого понятия, как внесение порядка в этот мир. Игра ребёнка - это творческий процесс.

Творчество - внешнее проявление способности психики к интеграции, упорядочиванию внешней и внутренней реальности. Творческий акт имеет следующие последствия: 
1. создается творческий продукт, имеющий собственную ценность;

2. возникает эмоциональный подъем;

3. повышается организованность содержания психики, его осмысленность;

4. расширяется сознание;

5. возрастает самосознание;

6. повышается сама творческая, организующая способность психики.

Во многих классических психологических теориях имманентно присутствует идея об интегрирующем воздействии творчества на психику.

3. Фрейд считал творчество сублимацией, то есть защитным механизмом, позволяющим преодолеть внутреннее напряжение и перевести сексуальную энергию в социально приемлемую деятельность, а также воплотить в продуктах творчества неосознаваемые стремления и переживания [10, с. 214].

А. Адлер рассматривает науку, искусство и другие области культуры как способ компенсации человеком своих недостатков [1, с. 46].

В гештальтпсихологии творчество - это приведение в единое целое (гештальт) разрозненных фактов, фрагментов знания, что приводит к озарению (Келлер, 1930) [3, c. 25].

Э. Фромм рассматривает творчество как «способность к глубокому осознанию своего опыта» [11, с. 89].

А. Маслоу пишет, что «творчество - универсальная функция человека, которая ведет ко всем формам самовыражения» $[8$, с. 311].

В отечественной психологии также есть максимально обобщенные, интегративные подходы к творчеству. Творчество понимается как феномен развития, обновления и предпосылка будущей адаптации (А.И. Суббето) [12, с. 167], как специфическая активность по преодолению отчуждения человека от природы (В. М. Вильчек) [2, с. 38], как механизм психического развития (Я. А. Пономарев) $[9$, с. 163].

Творчество - это процесс создания нового, который объективно осуществляется в природе или человеке. Продуктами творчества являются открытия, изобретения, новые художественные образы, произведения. Раскрывая сущность творчества, стоит отметить, что под творчеством понимается процесс создания чего-то нового для отдельного субъекта.

Во всех приведенных подходах творчество понимается как процесс, ведущий к исцелению и развитию психики, что в наших терминах есть интегративное развитие или интеграция. Это развитие происходит на разных уровнях, в соответствии с чем, феноменологически сильно отличается.

Многие деятели искусства так же указывали на исцеляющий характер художественного творчества. Что касается психологической практики, то психотерапевтическая роль творчества давно известна, и в настоящее время оформилась в самостоятельное направление практической психологии - арт-терапию. Арт-терапия представляет собой лечебно-профилактическую и коррекционную деятельность с использованием искусства, сложный синтез научных знаний педагогики, психологии, искусства, медицины, эргономики [7, с. 66]. Ее использование предполагает воздействие на процессы эмоциональной децентрации, эмоционально-волевую регуляцию, невербально-коммуникативную культуру, развитие сенсорной культуры личности.

Существуют различные взгляды на определение указанного термина, среди которых «арт-терапия» это:

- динамическая система взаимодействия между участником (ребенком, взрослым), продуктом его изобразительной творческой деятельности и арт-терапевтом (психологом, педагогом) в арттерапевтическом пространстве (Листовская Л.) [7, с. 67];

- здоровьесберегающая инновационная технология (Забара Л.) [5, с. 124];

- метод, связанный с раскрытием творческого потенциала индивида, освобождением его скрытых энергетических резервов, нахождением им оптимальных способов решения своих проблем (Евтушенко Г., Белова Е.) [4, с. 86];

- фактор личностно-ориентированного воспитания, который предполагает использование средств искусства для активизации личностного роста и творческого саморазвития (Иванова И., Косогорова Л.) [6, с. 49].

В современной психологической практике используются различные виды психотерапии через творческую деятельность, а именно: игровая терапия, сказкотерапия, драмотерапия, танцевальная терапия, музыкотерапия, куклотерапия, изотерапия, песочная терапия и др.

Приведенный краткий обзор подходов к пониманию и использованию творчества в психологической науке и практике показывает, что существует научная и практическая база для интерпретации творчества как интегративного механизма психики.

Для оценки уровня развития интегративных механизмов нами разработана 5-бальная шкала (уровни от -2 до +2). Показатели шкалы суммарно выражают результат 
действия как интегрирующих, так и дезинтегрирующих факторов. В совокупности их влияние создает уровень интеграции психики, который имеет характерную феноменологию и является наблюдаемым.

Приведем выдержку из таблицы феноменологии (преобладающего поведения) взрослого человека на творческой стадии по 5 уровням:

Уровень «-2». Деструктивная направленность во всем.

Уровень «-1». Конструктивная направленность на себя и деструктивная на окружение.

Уровень «0». Конструктивная направленность на себя и умеренно-конструктивная на физическое и социальное окружение.

Уровень «+1». Созидательная и творческая деятельность в различных сферах.

Уровень «+2». Творческое отношение к жизни, к себе, к людям, конструктивная направленность во всем.

Выдержка из таблицы феноменологии для детей дошкольного возраста (преобладающее поведение и состояние ребёнка) на творческой стадии по 5 уровням:

Уровень «-1». Деструктивная направленность во всем. Самоагрессия. Грызет ногти, бьется головой об стену, причиняет себе боль. Занимается онанизмом. Нет навыков самообслуживания и гигиены.

Уровень «-2». Конструктивная направленность на себя и деструктивная на окружение. Ломает игрушки, портит мебель, одежду, ломает карандаши, топчет клумбы, мучает животных, ломает деревья, бросается предметами. Не доводит начатое до конца.

Уровень «0». Конструктивная направленность на себя и умеренно-конструктивная на физическое и социальное окружение. Ленив. Отсутствие интереса к деятельности, безынициативен. Выполняет поручения только с подачи взрослого.

Уровень «+1». Созидательная деятельность в различных сферах. С удовольствием помогает по хозяйству. Аккуратно делает поделки на занятиях. По собственной инициативе поливает растения, ухаживает за животными. Настойчив в достижении цели.

Уровень «+2». Творческое отношение к жизни, к себе, к людям, конструктивная направленность во всем. Занимается созидательной деятельностью, создаёт на занятиях оригинальные поделки, необычно использует предметы. Самостоятельно ставит цели. Инициативен.
Из приведённых уровней таблиц феноменологии видно, что творчество как общепонимаемый психологический феномен характеризует только высший уровень интегративного развития психики - «+2». Таким образом, творчество в узком смысле слова, как деятельность по созданию уникальных продуктов, возникает на более высоком уровне развития психики.

Интегративные механизмы психики походят в онтогенетическом развитии несколько стадий: 1. Стадия телесной интеграции (ведущие механизмы этой стадии: дыхание, сон, физическая активность, взаимосвязь с природой). 2. Стадия эмоциональной интеграции (ведущие механизмы: эмоции и эмоциональная память, переживание). 3. Стадия творческой интеграции (ведущие механизмы: творчество и созидательная деятельность). 4. Стадия мыслительной интеграции (ведущий механизм - мышление). 5. Стадия социальной интеграции (социальные механизмы интеграции). 6. Стадия сознательной интеграции (ведущие механизмы: экстериоризация опыта, деятельность сознания). 7. Стадия духовной интеграции (механизмы духовной интеграции, любовь в широком смысле).

В онтогенезе каждая стадия интеграции развивается на основе предыдущих, надстраивается над ними. При недостаточном развитии предыдущих стадий интеграции невозможно развитие последующих. Более поздние стадии интеграции не компенсируют недостаток предыдущих стадий, либо компенсируют незначительно. Эта закономерность проявляется не только в онтогенетическом развитии, но и в процессе психокоррекционых занятий, а так же в педагогическом процессе. Данная закономерность выведена из практики психокоррекционной работы с детьми и взрослыми и экспериментально подтверждена. Это так называемый «закон последовательного развития интегративных механизмов» обладает большим объяснительным и прогностическим потенциалом при интерпретации различных психических феноменов и педагогических закономерностей.

Закон последовательного развития интегративных механизмов дает важный инструмент для социального воспитания: раннее формирование более высоких уровней интеграции возможно лишь на основе развития предыдущих, но не на основе их замещения или подавления, иначе происходит дезинтеграция самой системы интеграции. Для перехода на следующую стадию интегративного развития необходимо достичь хотя бы нулевого значения на предыдущей стадии. Например: невозможно добиться конструктивной направленности в поведении, если у ребенка преобладает страх и агрессия. Точно также невозможно научить ребенка нестандартному мышлению, если он склонен разрушать предметы и бить одноклассников. 
С точки зрения практики данная закономерность важна при создании технологий психокоррекции. Современные традиции компенсирующего обучения направлены на работу с интеллектуальным уровнем, хотя зачастую проблематика находится в слабости эмоциональной интеграции. Наши эксперименты с детьми с задержкой психического развития показывают, что оптимизация интегративных процессов телесного и эмоционального уровней автоматически приводит к улучшению умственной и творческой деятельности ребенка [15, с. 54]. Исходя из этой закономерности можно конкретизировать задачу психосоциального воспитания: при развитии ребенка важно прежде всего целостно сформировать систему интеграции психики, которая одновременно будет и системой защиты, и системой исцеления, и системой развития.

Для развития интегративных механизмов, в том числе творчества, необходимо учитывать, что каждой стадии развития интегративных механизмов соответствует определенный тип коммуникации и социального контроля. Телесная интеграция - физический контакт и физические методы воздействия. Этому соответствуют спортивное и танцевальное творчество, выращивание растений и забота о животных, подвижные игры. Эмоциональная интеграция - эмоциональный контакт и воздействие на эмоциональную сферу. Этому соответствуют музыкальное творчество, пение. Творческая интеграция - совместные игры и созидательная деятельность. Механизмы управления - эмоциональное и лидерство, ролевая позиция. Этой стадии соответствует художественное творчество, рукоделие, создание поделок, конструирование. Мыслительная интеграция - коммуникация как обмен информацией и идеями. Управление через соглашение, инструкции и общий интеллектуальный контекст. На данной стадии характерно интеллектуальное творчество, нестандартное мышление, постановка и решение новых задач, интеллектуальное лидерство. Социальная интеграция - партнерство, то есть функциональное разделение в достижении совместных целей. Способ управления - целеполагание. На этой стадии творчество представляет собой самостоятельную постановку социальных целей, организационное и деловое лидерство, принятие ответственности, создание социальных групп. Сознательная интеграция - экстериоризация опыта, обмен убеждениями, доверие, свобода и ответственность. Управление через предоставление возможностей. Творчество проявляется в осмыслении себя и мира, сочинительстве, философствовании, создании мировоззренческих концепций. Духовная интеграция - любовь и единение с Богом, обмен смыслами, растворение индивидуальности, безусловная вера. Способ управления: самоуправление. Творчество как жизнетворчество: спонтанное креативное созидательное существование во всех сферах бытия [16, с. 315].
При включении человека в определенный способ коммуникации, в нем развиваются соответствующие интегративные механизмы. В онтогенетическом развитии возникают новые уровни психики, появляются новые виды активности, в связи с этим, сменяются и ведущие интегративные механизмы. Интегративное развитие психики - это развитие в сторону большей целостности, которое характеризуется динамическим соответствием сложности организации (количеством элементов в системе) и уровнем организованности (мерой связи элементов). Мы считаем, что адекватная цель педагогического и психологического воздействия на человека - это обеспечение интегративного развития его психики.

Если на человека оказывается негативное воздействие или деструктивное влияние, то на интегративные механизмы психики ложится дополнительная нагрузка по их преодолению. Для творческой стадии интеграции деструктивными будут следующие факторы: жесткий контроль и ограничение свободы действий; насмешки и негативная оценка творчества и способностей ребенка, особенно, разрушение созданных продуктов; наказание за инициативу; бедность сенсорно-перцептивных стимулов, отсутствие адекватной социальной среды и поддерживающей коммуникации; бедный репертуар игр; постоянное аутсайдерство в игре; негативные внушения («у тебя ничего не получится», «ты ничего не умеешь» и тому подобное).

Из трактовки творчества как интегративного механизма психики следуют некоторые выводы:

Во-первых, творчество - это процесс с определенной мотивационной спецификой: он реализует базовую потребность в интеграции психики. Творчество не нуждается во внешней мотивации. Это самодетерминированный процесс.

Во-вторых, творчество возникает при определенном уровне интеграции психики, а именно на основе развития эмоциональной сферы, преобладания положительного эмоционального тона. Если в эмоциональной сфере человека преобладают негативные эмоции, творчество не может возникнуть. В этом случае необходимо развивать, либо корректировать предыдущие стадии интеграции - телесную и эмоциональную (восстанавливать дыхание, движение, устранять источники страхов и агрессии).

В - третьих, для развития творчества нужно дать человеку разнообразную предметную среду, благоприятный эмоциональный климат, свободу в деятельности. Обеспечить творческую безоценочную коммуникацию с референтными лицами. Создать игровые (ролевые) ситуации и дать примеры творческого поведения и деятельности. Включить в совместную созидательную де- 
ятельность.

В-четвёртых, обучение убивает творчество, творчеству не нужно учить как алгоритму. Алгоритмы, паттерны, образцы, смыслы - это процессы следующей стадии интеграции - мыслительной, которая приходит на смену творчеству. В современной педагогической практике развитие творчества понимается в основном как обучение художественным ремеслам, искусству. Перспектива соединения образования и творчества видится нам не как обучение творчеству (ему не надо учить, оно - природа человека), а как использование творчества в качестве инструмента обучения, то есть творческая интеграция знаний.

В-пятых, творчество как интегративный механизм психики, обладает уникальными особенностями: оно проявляется на всех стадиях, доступно внешней организации, а также является социально полезным феноменом. Мы рекомендуем развивать любые виды творческой деятельности для социального и психического оздоровления населения.

Высказанное в статье понимание сущности творчества подтверждено экспериментально на группах детей и взрослых с различным уровнем интеграции психики $[13$, с.142]. На основе авторской концепции интеграции психики были проведены 12 детских и молодёжных лагерей. Эмпирические и экспериментальные исследования в этих лагерях показали, что при восстановлении интегративных механизмов телесной и эмоциональной стадии (сна, связного дыхания, спонтанного движения, положительного эмоционального фона) у испытуемых спонтанно возникали творческие процессы в рисунке, поэзии, танце, музыке. При этом, чем выше был изначальный уровень интеграции психики у группы, тем более необычными были их творения. Например, дети-сироты, пострадавшие в результате военных действий, на занятиях по арт-терапии рисовали могилы и взрывы, актуализируя и интегрируя свою эмоциональную проблематику. Дети из социального актива, у которых был базовый положительный эмоциональный фон, на занятиях с такой же программой, рисовали яркие картины, а на четвёртом занятии сами начали роспись по телу - «бодиарт» и сделали живую выставку фантазийных животных.

При достижении высокого уровня интеграции психики, дети начинают заниматься не только художествен- ным, но и социальным творчеством. Например, старшие девочки в лагере «Актив-релакс» сами, по собственной инициативе и без помощи вожатых, устраивали каждый день новое, костюмированное сказочное представление в палате для малышей, чтобы те с желанием уходили раньше всего лагеря спать. Сами сочиняли сказку, репетировали, брали в костюмерной костюмы. Старшие юноши сами договорились с соседним лагерем и организовали турнир по футболу, хотя ни физрука, ни спортивных занятий в программе нашего лагеря не было. Сами создали команду, тренировались, организовали игры, нашли судей и, в итоге, победили.

В соответствии с выделенными стадиями интеграции психики можно на каждой стадии описать наиболее высокий уровень развития, когда феноменологически будет проявлено творчество. Телесная интеграция -воспитание животных и растений; кулинарное творчество; танец, цирковое искусство; самооздоровление, «здоровый образ жизни», строительство тела (фитнес, бодибилдинг и др.), спорт высших достижений; туризм ( в том числе охота и рыбалка), экстремальный спорт; интегративные практики самосовершенствования (йога, цигун и др.), боевые искусства, сексуальное творчество. Эмоциональная интеграция - игра на музыкальных инструментах, диджеинг, исполнение и сочинение музыки и песен; спортивные игры. Творческая интеграция - рукоделие, прикладное искусство, художественное творчество; дизайн внешности, одежды и быта; строительство и отделка помещений; инженерная деятельность и конструирование; изобретательство. Мыслительная интеграция - стихосложение, сочинительство, инсайты и прозрения, решение нестандартных задач, создание концепций и теорий, научное творчество, интеллектуальные игры и спорт. Социальная интеграция - организация и руководство социальными группами (в том числе создание семьи), управление социальными процессами, педагогическое творчество (в том числе воспитание собственных детей), экономическое и социальное предпринимательство, карьера. Сознательная интеграция - создание собственного социального имиджа (в том числе вэбсайтов), журналистика (в том числе блоги и видеоблоги), литературное творчество, создание текстовых художественных произведений (в том числе дневников и мемуаров). Духовная интеграция - создание психологических, религиозных и философских концепций, теорий, и практик; духовная трансценденция и трансформация.

\section{ЛИТЕРАТУРА}

1. Адлер А. Практика и теория индивидуальной психологии. - М.: Академический проект, 2015. - 240 c.

2. Вильчек В.М. Алгоритмы истории. - М.: Прометей, 1989. - 132 с.

3. Дикая Л.А., Дикий И.С. Творческий мозг: монография / Л.А. Дикая, И.С. Дикий; Южный федеральный университет. - Ростов-на-Дону: Издательство Южно- 
го федерального университета, 2015. - 218 с.

4. Евтушенко Г.Н., Белова Е.А. Роль артпедагогики и арт-терапии в гармоничном развитии ребенка с проблемами // Интерактивная наука. - 2016. - № 2. - C. 85-88.

5. Забара Л.И., Якина Л.Н. Арт-терапия как инновационная технология социально-педагогической деятельности с детьми: к проблеме теории и методологии // Педагогические технологии. - 2017. - № 3. - С. 122-131

6. Иванова И.В., Косогорова Л.А. Арт-терапия как средство самопознания и развития творческого потенциала личности // Вестник образовательного консорциума Среднерусский университет. Серия: Гуманитарные науки. 2014. № 3. С. 48-50.

7. Листовская Л.В. Арт-терапия - форма организации творческого процесса // Известия Казанского государственного архитектурно-строительного университета. 2014. № 2 (28). С. 65-69.

8. Маслоу А.Х. Дальние пределы человеческой психики. - СПб.: Питер, 2018. - 448 с.

9. Пономарев Я.А. Актуальные проблемы психологии творчества // Вопросы психологии. - 1982. - № 5. - С. 161-166.

10. Фрейд 3. Введение в психоанализ. - М.: Азбука, 2017. - 448 с.

11. Фромм Э. Кризис психоанализа. - М.: АСТ, 2017. - 256 с.

12. Человек и общество. Ноосферное развитие / под ред. В.Н. Василенко, С.И. Григорьева, В.И. Петрушева, А.И. Суббето. - Белгород: Белгородская областная типография, 2011. -480 c.

13. Шемет И.С. Интеграция психики: концепция, метод, эксперимент. М.: Редакционно-издательский центр Консорциума «Социальное здоровье России», 2006.- 192 c.

14. Шемет И.С. Методы интеграции психики: автореф. дис. на соиск. учен. степ. докт. психол. наук (19.00.01) - Москва, 2006. - 54 с.

15. Шемет И.С. Потребность в интеграции и её реализация на разных ступенях интегративного развития человека // Вестник Костромского государственного университета им. Н.А. Некрасова. Серия Психологические науки: «Акмеология образования»: Науч.-методич. журнал - Кострома, 2009. - Т. 15. - С. 50-55.

16. Шемет И.С. Системогенез жизнедеятельности // Системогенез учебной и профессиональной деятельности: матер. IV Всерос. науч.-практич. конф./ под науч. ред. Ю.П. Поварёнкова. - Яр: Изд-во ЯГПУ, 2009. - С. 314-316.

(c) Шемет Ирина Сергеевна (irashemet@yandex.ru).

Журнал «Современная наука: актуальные проблемы теории и практики»

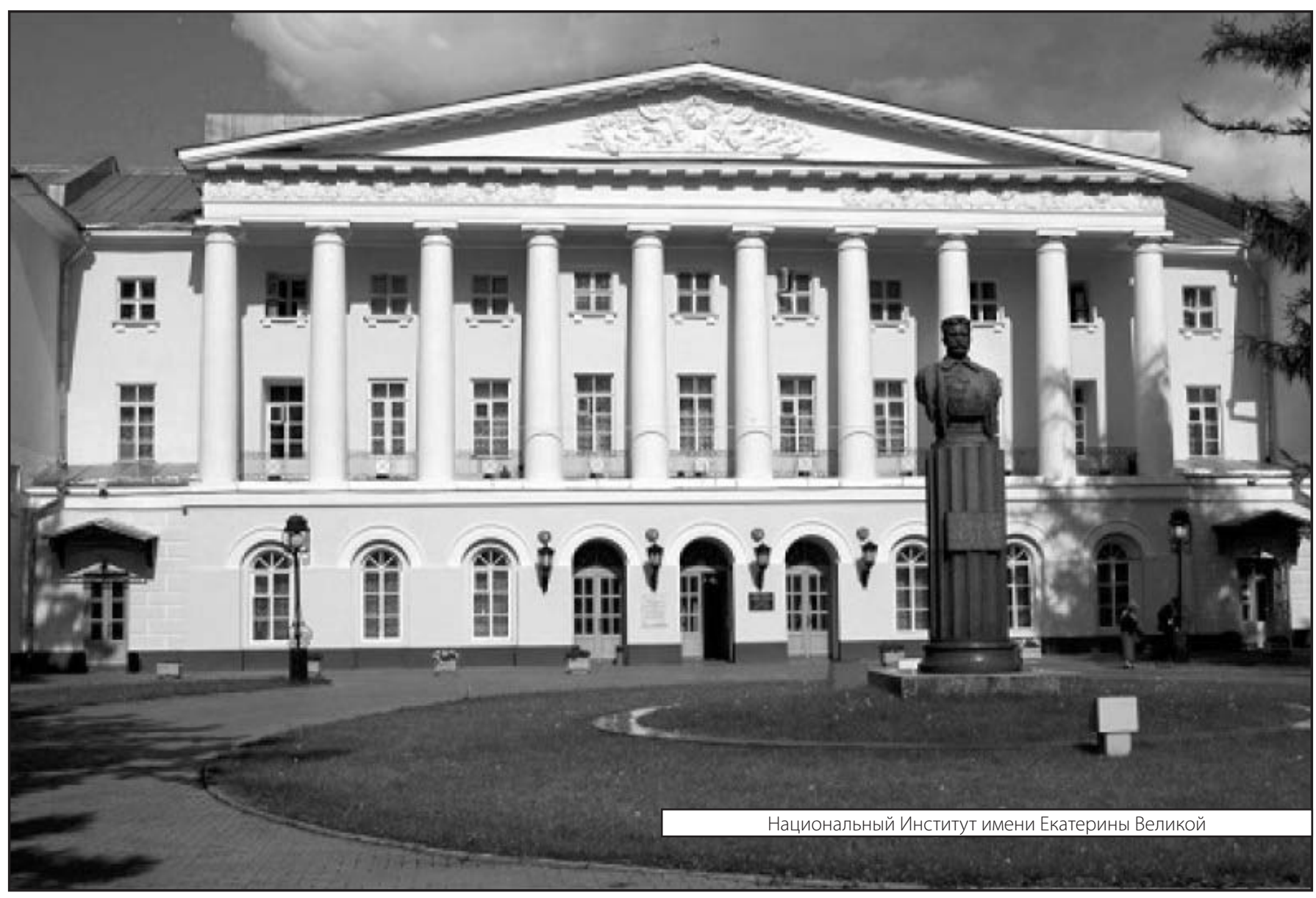

